\title{
A novel method to extract juglone from Juglans mandshurica waste branches using a water-in-oil microemulsion
}

\section{Chunying Li}

Northeast Forestry University

\section{Xianming Meng}

Northeast Forestry University

Mengfei Tian

Northeast Forestry University

Shen Li

Northeast Forestry University

Yao Tian

Northeast Forestry University

Tingting Wang

Northeast Forestry University

Chunjian Zhao ( $\nabla$ zcjsj@163.com )

Northeast Forestry University https://orcid.org/0000-0003-2827-1999

\section{Research Article}

Keywords: Juglans mandshurica, juglone, waste branches, microemulsion

Posted Date: March 11th, 2021

DOl: https://doi.org/10.21203/rs.3.rs-248109/v1

License: (c) (i) This work is licensed under a Creative Commons Attribution 4.0 International License. Read Full License

Version of Record: A version of this preprint was published at Waste and Biomass Valorization on October 19th, 2021. See the published version at https://doi.org/10.1007/s12649-021-01611-x. 


\section{Abstract}

Pruning of Juglans mandshurica produces a lot of waste branches which are potentially rich source of juglone. However, they are usually discarded as waste. Given that, the water-in-oil microemulsion was proposed, aiming at developing a novel and efficient microemulsion-based microwave-assisted extraction $\triangle M B M A E \rrbracket$ method. By which juglone in the Juglans mandshurica waste branches could be obtained.

In our experiment, the waste branches powder was added to the MBMAE system. Under the best microemulsion system: (tween 80: n-propanol : n-hexane : water $\ 27 \%: 13.5 \%: 4.5 \%: 55 \%$ ), the PH of the microemulsion solution of 5.6 , microemulsion - Juglans mandshurica branches powder of $20: 1(\mathrm{~mL} / \mathrm{g})$, operating temperature of $40^{\circ} \mathrm{C}$ and operating time of $63 \mathrm{~s}$, operating power of $400 \mathrm{~W}$, the juglone yield was $4.58 \mathrm{mg} / \mathrm{g}$. The results were that the extraction yield applying the MBMAE method were 1.86-fold and 6.65-fold that of microwave-assisted extraction applying ethanol (Ethanol-MAE) and heat reflux extraction by ethanol (Ethanol-HRE), respectively. Obviously, the MBMAE method could be used as an alternative to traditional extraction methods to extract juglone.

\section{Statement of Novelty}

A large number of waste branches from Juglans mandshurica pruning are often discarded as waste. Based on the concept of green development, this work proposes for the first time the extraction and utilization of juglone from the waste branches of Juglans mandshurica. However, a certain problem such as low efficiency, high cost, and complicated operation is existing in traditional extraction method for juglone. Consequently, a special microemulsion system for juglone was established for the first time, and on this basis, the application of MBMAE method to the extraction of juglone was also proposed for the first time. It provides data support for the extraction of juglone from other materials or plants.

\section{Introduction}

Juglans mandshurica, a fast-growing deciduous broadleaf tree and a member of the Juglandaceae family, is widely distributed in the northeast of China, South America, North America, Oceania, Southeastern Europe, Eastern Asia [1,2,3,4] As one of the precious tree species, Juglans mandshurica is not only excellent in wood, but also has multiple medicinal values $[5,6,7]$. Researches have shown that the stem barks, leaves, roots and fruits of Juglans mandshurica which contain polyphenols, naphthoquinones and tetralones $[8,9,10,11,12]$ having obvious pharmacological activity curing cancer, kidney deficiency, inflammation $[13,14,15,16]$.

In forestry production, pruning measures are often taken to adjust the reasonable distribution of nutrients, control pest and disease, protect soil and restrain the excessive growth so as to keep the trees healthy [17]. Failure to properly pruning the trees will make the trees more susceptible to disease, which may reduce forest quality or obvious yield of active component unevenness $[18,19]$. Pruning is, therefore, an 
essential skill for tree growers. But pruned branches are often discarded as waste, and these branches are usually rich in biologically active ingredients. Researchers found that the waste branches from Juglans mandshurica pruning contain a certain amount of juglone [20,21]. Juglone has been suggested as a potential drug candidate for treating cancer, anemia, diabetes and inflammation [22,23]. Meanwhile agricultural waste reutilization has been adopted as alternative to improve sustainable technologies and improve resource utilization $[24,25]$. Therefore, this research was dedicated to develop an efficient and novel technology to obtain juglone from the waste branches of Juglans mandshurica to maximize resource utilization.

Dipping extraction, decocting method and soxhlet extraction were traditional extraction methods for juglone $[26,27]$. However, these traditional extraction methods face some problems, such as low efficiency, complicated operation, large amount of solvents consumed and have certain toxicity $[28,29,30]$. Therefore, it is particularly necessary to develop a novel and efficient extraction method for juglone.

Microemulsion is a transparent or translucent liquid stable mixture system which composed of oil, water, surfactant, co-surfactant and electrolyte $[31,32,33]$. Compared to the conventional extractants, microemulsion system has various excellent properties, such as the nanometer scale, large specific surface area, high selectivity and rapid coalescence [34,35]. In view of the advantages of microemulsion extraction (ME), more and more researchers have applied it to the fields of food, medicine, sewage treatment, heavy metal recovery and protein extraction $[36,37,38,39]$.

Considering the advantages of ME, the water-in-oil microemulsion was proposed for the first time and

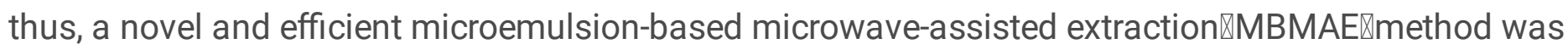
developed. Which was applied to the juglone obtaining in Juglans mandshurica waste branches. This is also in line with the full use of waste resources to complete the trend of green development $[40,41,42]$. Moreover, response surface analysis (RSM) based on BBD was applied to optimize the MBMAE of juglone.

\section{Materials And Methods}

\section{Materials and reagents.}

Discarded branches of Juglans mandshurica were picked from Forest experiment station, Maoer mountain, Harbin City, Heilongjiang Province, China. The branches of Juglans mandshurica were placed into $40^{\circ} \mathrm{C}$ dryer. Which were smashed into powder (60 mesh).

Juglone standard (HPLC $\geq 98 \%$, Aladdin Chemistry Co., Ltd.), the structure of juglone is seen in Fig 1. Other reagents were from Yuanye Chemical Reagent Co. (Shanghai, China).

\section{Determination of juglone}


Juglone was determined by high performance liquid chromatographic (HPLC) (1206 Infinity, Agilent Technology Co., Ltd.). The Diamonsil $C_{18}$ column ( $250 \mathrm{~nm} \times 4.6 \mathrm{~mm}, 5 \mu \mathrm{m}$, Dikma, Beijing) was used for HPLC analysis. The elution process was $0-30 \mathrm{~min}, 0.2 \%$ phosphoric acid aqueous solution (A) $50 \%$, methanol (B) $50 \%$. The flow rate and injection volume were $1.0 \mathrm{~mL} / \mathrm{min}$ and $20 \mu \mathrm{L}$. The detection wavelength and column temperature were set at $250 \mathrm{~nm}$ and $30^{\circ} \mathrm{C}$. The HPLC result of juglone was shown in Fig 2. Taking the concentration of juglone standards as the abscissa and the average value of the chromatographic peak area as the ordinate, a linear regression equation and correlation coefficient were generated. $\left(y=100599 x-133.58, R^{2}=0.9990\right)$.

\section{Establishment of microemulsion system}

Determining the solubility of juglone in different accessories, suitable components for the preparation of juglone microemulsion extraction system could be considered. Add $0.5 \mathrm{~g}$ powder, $10 \mathrm{~mL}$ oil phase (walnut oil, olive oil, isooctane, tea oil, n-hexane) and co-surfactant (n-butanol, n-pentanol, PEG-400, propanol, Transcutol HP), respectively into a centrifuge tube, ultrasonic to fully dissolve, shake for $48 \mathrm{~h}$ to reach dissolution equilibrium, centrifuged, the supernatant was passed through $0.45 \mu \mathrm{m}$ organic filter membrane for HPLC analysis. Then, $1.0 \mathrm{~g}$ surfactants (CTMAB, P204, SDBS, AOT, tea saponin, tween 80) was added into the sieved oil phase and co-surfactant respectively, and the volume of liquid consumed for the complete dissolution was recorded. Solubility judgment of surfactants type is seen in table1. Thus, surfactants with greater solubility in the co-solvent and the oil phase were obtained by sieving.

Mixed surfactants were consisted of surfactants and co-surfactants in a certain ratio(w/w). Subsequently added the mixed surfactant to the oil solvent. After that, the water was added until it was clear and transparent. In order to judge whether the mixed solution was a microemulsion system, the Tyndall phenomenon under light irradiation was observed. Particle size of microemulsion system was determined by Zeta analyzerखBrook Haven Instruments Corporation).

In order to verify the type of optimal microemulsion system obtained囚add $400 \mathrm{uL}$ methylene blue and Sudan red respectively into the microemulsion system『observe the diffusion rate of methylene blue and Sudan red.

\section{Extraction procedure}

In order to further prove that the MBMAE method could improve the extraction rate of juglone in the branches of juglans mandshurica, the extraction effect of juglone by MBMAE method, microwaveassisted ethanol extraction (Ethanol-MAE) and traditional ethanol heat reflux extraction (Ethanol-HRE) were compared (Table 2).

\section{Microemulsion-based microwave-assisted extraction (MBMAE)}

Added $2.0 \mathrm{~g}$ Juglans mandshurica waste branches powder in a $100 \mathrm{~mL}$ conical flask. After that, $40 \mathrm{~mL}$ of microemulsion was added to the conical flask at certain $\mathrm{PH}$. Then the mixture of microemulsion and 
sample were extracted on microwave under certain conditions (Table 2). The solutions were filtered and collected, centrifuged at $12,000 \mathrm{rpm} / \mathrm{min}$ for 10 minutes, and the supernatant was passed through 0.45 $\mu \mathrm{m}$ organic filter membrane for HPLC analysis.

\section{Microwave-assisted extraction (MAE)}

MAE was completed according to the above method of MBMAE.

\section{Heat reflux extraction (HRE)}

$2.0 \mathrm{~g}$ juglans mandshurica branches powders with $40 \mathrm{~mL}$ ethanol refluxed at $60^{\circ} \mathrm{C}$ for $2.5 \mathrm{~h}$. The solutions were filtered and collected, centrifuged at $12,000 \mathrm{rpm} / \mathrm{min}$ for 10 minutes and the supernatant was passed through $0.45 \mu \mathrm{m}$ organic filter membrane for HPLC analysis.

\section{MBMAE optimization}

\section{Single-factor experimental design.}

Liquid-solid ratio, microwave power, microemulsion $\mathrm{PH}$, extraction temperature and extraction time were chosen as single-factor, from which an initial range of extraction parameters could be acquired.

\section{Experimental design of RSM}

The relationship between independent variable and dependent variable was analyzed by RSM. Based on the single factor experiment, four factors were selected to perform a three-level BBD (Table 3), from which the interaction of each factor on juglone yield could be taken (Table 4).

\section{Statistical analysis}

Three times were repeated on all experiments. Mean \pm SD $(n=3)$ was the expression of results. The juglone yield could be calculated as follows: see formula 1 in the supplementary files.

$\mathrm{Y}$ is juglone yield $(\mathrm{mg} / \mathrm{g}) ; \mathrm{k}$ is dilution factor; $\mathrm{C}$ is juglone concentration $(\mathrm{mg} / \mathrm{mL}) ; \mathrm{V}$ is solvent volume $(\mathrm{mL}) . \mathrm{M}$ is mass of Juglans mandshurica branches powder $(\mathrm{g})$.

\section{Results And Discussion}

\section{Preparation and determination of microemulsion prescription}

\section{Selection of oil phase, surfactant and co-surfactant}

The formation of microemulsion requires that the oil phase molecules and the interface membrane molecules should maintain proper permeability and contact, and the molecular weight of the oil phase should not be too large [43]. The ability of the oil phase to form microemulsions is related to the molecular size of the oil phase. Generally, the small molecular oil phase was easy to form 
microemulsions, while macromolecular oil phase was not easy to form microemulsions [44]. Therefore, the oil phases selected in this study were all oils with short molecular chains and commonly used medicinal microemulsions, such as walnut oil, olive oil, isooctane, tea oil, n-hexane, and castor oil. These oils were non-toxic and irritating to the body. Screen the oil phase of the microemulsion based on the solubility of juglone in the oil phase. The results were shown in Fig. $3 \mathrm{a}$, and the solubility of n-hexane, castor oil and isooctane on juglone extract was relatively high. Therefore, n-hexane, castor oil and isooctane were selected as the oil phase for subsequent microemulsion system screening.

In the process of microemulsion formation, co-surfactants could increase the solubility of surfactants, reduce the surface tension of the interfacial film of microemulsion system and increase its fluidity, and promote the formation of microemulsions [45]. Commonly used co-surfactants include lower alcohols, organic amines, mono- and di-alkyl glycerides [46]. In this experiment, n-butanol, n-pentanol, PEG-400, npropanol, and Transcutol HP was selected as co-surfactants. As shown in Fig. 3 b, n-propanol and nbutanol had a higher solubility for juglone. Therefore, $n$-pentanol, $n$-propanol and n-butanol were selected as co-surfactants to further screen the microemulsion system.

Surfactants, known as amphiphiles, were the main components of the microemulsion to solubilize the target compound. In the experiment, the most commonly used surfactants CTMAB, P204, SDBS, AOT, tea saponin, and tween 80 in pharmacy were selected as preliminary screening chemicals. Since the selected surfactant contains both solid and liquid, the solubility of the surfactant in the selected oil phase and cosurfactant was used as an index to determine the surfactant solution. As shown in Table 1 and Table 5, tween 80, OTAC and P204 showed extremely soluble or easily soluble in the selected oil phase and cosurfactant. Therefore, it was determined that tween 80 , OTAC and P204 were the suitable surfactant of this system.

\section{Screening of microemulsion system}

The oil phase, co-surfactant and surfactant obtained were tested for emulsion formation. Since castor oil, n-pentanol, OTAC and P204 cannot form emulsion, four emulsification systems were finally obtained, namely Tween 80 - n-hexane - n-propanol, Tween 80 - n-hexane -n-butanol, Tween 80 - iso-octane - npropanol, Tween 80 -iso-octane - $n$-butanol. The particle size analysis and Tyndall effect analysis were performed on the above four systems. As shown in Fig. 4, except for the Tween 80 - iso-octane - $n$ propanol system, the other three systems all meet the microemulsion particle size requirements of 10-100 $\mathrm{nm}$ and all four systems could produce the Tyndall effect (Fig. 4). Therefore, three kinds of microemulsion systems were actually obtained. In addition, by drawing a pseudo ternary phase diagram and calculating microemulsion area, it was further found that the microemulsion area formed by Tween 80-n-hexane-n-propanol was the largest (Fig. 5 a). Therefore, the final selected microemulsion system was tween 80 - n-hexane - n-propanol.

\section{Screening of the distribution ratio of different components in the microemulsion}


Tween 80 - $\mathrm{n}$-hexane - $\mathrm{n}$-propanol microemulsion system in various proportions was adjusted to obtain a higher juglone yield. As shown in Table 5, when tween 80: n-propanol: $n$-hexane: water $=27 \%: 13.5 \%$ : 4.5\%: $55 \%$, the juglone yield was the highest, which was $3.28 \mathrm{mg} / \mathrm{g}$ (Table 6). Therefore, it is determined that the special microemulsion system of juglone, tween 80 : propanol: $n$-hexane: water $=27 \%: 13.5 \%$ : 4.5\%: 55\%. The structure of each component in the microemulsion is also presented in Fig. 6.

\section{Determination of microemulsion type}

The diffusion rate of Sudan red and methylene blue dye in the established microemulsion system was compared to determine the type of microemulsion system. As shown in Fig. 7, the time which the Sudan red diffusing to the full bottle was shorter than methylene blue. It proved that the juglone -specific microemulsion system was a water-in-oil (W/O) type, which was consistent with the reports on the fatsoluble components being suitable for extraction by W/O microemulsion [47].

\section{Extraction mechanism}

Tween 80 is nonionic surfactant which have high surface activity, strong solubilization, low toxicity and hemolysis, and a wide applicable pH range [48]. As shown in Fig. 8, one ester group, three hydroxyl groups and five ether groups are included in its structure. During extraction, the oxygen atoms on the ester group, ether group, and - $\mathrm{OH}$ in the Tween 80 form hydrogen bonds with the phenolic hydroxyl groups in the juglone to achieve a strong hydrogen bond extraction effect. Meanwhile, the oxygen atoms contained in Tween 80 and juglone have different electronegativity due to the different connected groups. Therefore, the empty orbitals of the oxygen atoms in the ester, hydroxyl, and ether groups in tween 80 and the lone pair of electrons in the oxygen atom in the hydroxyl group of juglone can form a coordination bond, which plays a critical role in coordination extraction. In addition, the $\mathrm{H}^{+}$from the dissociation of juglone could also produce coordination with the oxygen atom in tween 80 to make tween 80 positively charged, forming electrostatic interaction with the dissociated juglone anion to complete extraction process. The chemical effect of extracting juglone by tween 80 is theoretically the result of coordination, hydrogen bonding and static electricity interaction.

\section{Single factor experiments}

In order to define the experimental domain for each factor and establish a control method, some factors which maybe have a greater impact on the results were explored [49]. Each factor was investigated, other parameters were set at constant values [50,51]. Five main influencing factors, microemulsion -powder ratio $(10-30 \mathrm{~mL} / \mathrm{g})$, experimental temperature $\left(30-50^{\circ} \mathrm{C}\right)$, experimental time $(50-70 \mathrm{~s})$, microwave power (300-500 W) and microemulsion $\mathrm{PH}(5-6)$ were studied, and the results were discussed.

\section{Effect of liquid-solid ratio}

The number of "pools" is contained in microemulsion which determines the extraction capacity of microemulsion for juglone. The extraction saturated easily due to the insufficient amount of extractant. 
As shown in Fig. 9 a, the juglone yield was improved with the increase of liquid-solid ratio from 10 to 20 $\mathrm{mL} / \mathrm{g}$, when it reached $20: 1$, the juglone was extracted completely, and then the juglone yield would not increase with increasing the amount of extractant. Therefore, in regarding of yield and cost, the liquidsolid ratio of 20:1 was suitable for the following optimization experiments.

\section{Effects of microwave power}

Selected the extraction power from $300 \mathrm{~W}$ to $700 \mathrm{~W}$ for experiment to obtain the relationship between it and juglone yield. Juglone yield was the highest at $400 \mathrm{~W}$, when the power continued to increase, the yield of juglone decreased (Fig. 9 b). The reason for this phenomenon could be explained as: the electromagnetic field generated by microwave extraction increased with the increase of power. With the increase of power, the gradually increasing magnetic field promoted the acceleration of electron migration in the extract. When the power was too strong, the dissociation of juglone molecules in the microemulsion system accelerated under the induced magnetic field. The charged ions in the microemulsion were more concentrated at the end of the gel core, forming an electrostatic shielding field. which reduced the binding ability of the dissociated juglone ions with tween 80 . Juglone yield was reduced under the above conditions. Therefore, considering environmental protection and yield, $400 \mathrm{~W}$ was selected as the power condition for subsequent experiments.

\section{The effect of different microemulsion $\mathrm{PH}$}

The $\mathrm{pH}$ of the microemulsion system is also one of the important factors affecting the extraction results. Due to a phenolic hydroxyl existed on the structure of juglone, the structures of juglone were stable at the relatively acidic microemulsion solution. The effect of different $\mathrm{pH}$ microemulsion solution on the juglone extraction yield was investigated with the range $\mathrm{PH}$ of 4.0-6.0. Adjusted microemulsion $\mathrm{pH}$ with $1.0 \mathrm{~mol} / \mathrm{L}$ hydrochloric acid. And 5.5 was the most suitable $\mathrm{PH}$ for extracting juglone as shown in Fig. 9 c. PH mainly affects the extraction rate by influencing electrostatic interaction. When the $\mathrm{PH}$ was too low, although it was beneficial for tween 80 to form positively charged ions, excessive $\mathrm{H}^{+}$may interact with the negatively charged polar head on the surface of the reverse micelle gel core to produce a shielding effect. Which made the negatively charged juglone ions could not be extracted into the "pool" and the extraction rate was decreased. Furthermore, excessive $\mathrm{H}^{+}$inhibited the dissociation of juglone and reduced the number of negatively ions produced juglone ionization, thereby weakening the electrostatic extraction effect with tween 80 . Under high $\mathrm{PH}$ conditions, the amount of $\mathrm{H}^{+}$coordinated with tween 80 will also decreased, which would reduce the positive charge of tween 80 and decrease the electrostatic effect. Therefore, 5.5 was regarded as the most suitable $\mathrm{PH}$ for subsequent research.

\section{Effect of temperature}

Microwave temperature is a crucial parameter influencing juglone yield. As shown in Fig. $9 \mathrm{~d}$, the juglone yield gradually increased $\nabla 20^{\circ} \mathrm{C}$ to $40^{\circ} \mathrm{C} \otimes$, and then the yield was negatively correlated with temperature. This phenomenon could be explained that, at low temperature, the low movement rate of juglone made it could not be well dispersed in the microemulsion to interact with tween 80 . When the temperature was 
higher than $40^{\circ} \mathrm{C}$, the juglone molecules begin to decompose, which would also reduce the extraction rate. Considering energy consumption and production efficiency, $40^{\circ} \mathrm{C}$ was chosen as the optimum temperature.

\section{Effect of time}

To evaluate the effect of microwave time on the juglone yield, microwave time with range of 40-80 $s$ were performed. As shown in Fig. 9 e, the juglone yield increased with the microwave time from 40 to $60 \mathrm{~s}$. At $60 \mathrm{~s}$, the juglone yield reached the maximum and then decreased with the further increase of microwave time. This result could be attributed to the fact that as the extraction time increasing, the contact between juglone and microemulsion becomes more and more sufficient, and the yield also increases. However, when the time exceeded $60 \mathrm{~s}$, the temperature of the microemulsion increased, and the stability of juglone destroyed, which led to a decrease in yield. So the extract time of $60 \mathrm{~s}$ was chosen for the further experiment.

\section{Response surface analysis for juglone yield}

Based on pre-experiments, microemulsion $\mathrm{PH}$, microwave power, experimental temperature and experimental time were closely related to juglone yield. Considering the results of single factor experiments, these factors were investigated and then optimized by using RSM.

The interaction between some factors that had a greater impact on juglone yield was tested through BBD. The quadratic regression model was established relating the response to the variables, as described by Eq. (2). The arrangement and results were shown in Table 4 . See formula 2 in the supplementary files.

Among them, $Y$ was juglone yield $(\mathrm{mg} / \mathrm{g}), \mathrm{X}_{1}, \mathrm{X}_{2}, \mathrm{X}_{3}$ and $\mathrm{X}_{4}$ were microemulsion $\mathrm{pH}$, extraction temperature $\left({ }^{\circ} \mathrm{C}\right)$, microwave power $(\mathrm{W})$ and extraction time $(\mathrm{s})$, respectively.

Model-P<0.0001, Model-F=19.44, which displayed the model was extremely significant. As the value of the lack-of-fit term, 0.0826 was greater than 0.05 indicating that was not significant. Which represented the model was effective in fit and credibility, the test error was small. $R^{2}=0.9511$, which proved that the equation could fit $95.11 \%$ of the juglone yield, that was, $95.11 \%$ of the change in juglone yield came from the selected variables. In summary $\Downarrow$ this model could be used to analyze and predict juglone yield. From the F value in Table7, the order of the influence of various factors on juglone yield was: experimental time $\left(X_{4}\right)>$ microemulsion $\mathrm{PH}\left(\mathrm{X}_{1}\right)>$ experimental temperature $\left(\mathrm{X}_{2}\right)>$ experimental power $\left(\mathrm{X}_{3}\right)$.

The 3D models of the influence of various factors in MBMAE on juglone yield were shown in Fig.10. We found that the output of juglone was positively correlated with influencing factors. Which included microemulsion $\mathrm{PH}$, extraction temperature, extraction time and microwave power. The most suitable conditions optimized by BBD were: microemulsion $\mathrm{PH}$ of 5.62, experimental time of $63.24 \mathrm{~s}$, experimental temperature of $40.81^{\circ} \mathrm{C}$ and experimental power of $378.58 \mathrm{~W}$. And $4.60 \mathrm{mg} / \mathrm{g}$ was the maximum juglone yield in the prediction model. Taking into account the limitations of actual conditions, the actual 
extraction conditions of the experiment were performed at microemulsion $\mathrm{PH}$ of 5.60, operating time of $63 \mathrm{~s}$, operating temperature of $40^{\circ} \mathrm{C}$, extraction power of $400 \mathrm{~W}$ for 3 cycles. The actual output of juglone was $4.58 \mathrm{mg} / \mathrm{g}$ on average, basically accordant with the predicted value. It showed that the extraction process of juglone optimized by BBD was stable and reliable.

\section{Comparison of different extraction methods}

Juglone yields obtained by the process of MBMAE, Ethanol-MAE and Ethanol-HRE were compared (Table 4). The highest juglone yield was $4.58 \mathrm{mg} / \mathrm{g}$, and that was 1.86 -fold and 6.65 -fold of Ethanol-MAE and Ethanol-HRE, respectively. It could be demonstrated that during the MBMAE, juglone was selectively solubilized into the reverse micelle system through the coordination and hydrogen bonding of the microemulsion and juglone, which was more selective than MAE and HRE. Therefore, MBMAE is an alternative with stronger comprehensive capabilities to the conventional methods of extracting juglone from branches of Juglans mandshurica.

\section{Conclusion}

In this study, the novel microemulsion system and MBMAE method were first used to obtain juglone from the waste branches of Juglans mandshurica. Under the optimal extraction parameters screened by Single factor experiment and RSM, the highest juglone yield was $4.58 \mathrm{mg} / \mathrm{g}$. And that was 1.86 -fold and $6.65-$ fold of Ethanol-MAE and Ethanol-HRE, respectively. MBMAE was an efficient, rapid, and promising technique for extracting juglone from branches of Juglans mandshurica. At the same time, it provides data support for the potential of microemulsion to be an excellent alternative solvent for extracting juglone from other plant materials, products or wastes.

\section{Declarations}

Acknowledgement This work was financially supported by the Fundamental Research Fund for Central Universities (2572017CA11). Heilongjiang Touyan Innovation Team Program (Tree Genetics and Breeding Innovation Team).

Declaration of Interest Statement We declare that we have no financial and personal relationships with other people or organizations that can inappropriately influence our work. There is no professional or other personal interest of any nature or kind in any product, service or company that could be construed as influencing the position presented in the manuscript entitled "A novel method to extract juglone from Juglans mandshurica waste branches using a water-in-oil microemulsion".

Author Contributions Chunjian Zhao and Chunying Li conceived the underlying idea of the study; Xianming Meng and Mengfei Tian contributed to the practical aspects of the research work; Shen Li $\mathbb{Y}$ Yao Tian and Tingting Wang analyzed the data; and Chunying Li, Xianming Meng and Mengfei Tian wrote the manuscript. 


\section{References}

1. Wang, R.J., Wang, S., Xia, Y.J., Tu, M.W., Zhang, L.J., Wang ,Y.M .: Antitumor effects and immune regulation activities of a purified polysaccharide extracted from Juglan regia. Int. J. Biol. Macromol. 72, 771-775 (2015)

2. Zhang, Y.W.,Lin, H., Li, S.S.,Chen, J.B., Sun, Y S,Li, Y.X.: High-speed counter-current chromatography assisted preparative isolation of bioactive compounds from stem bark of Juglans mandshurica. J. Sep. Sci. 40 (3), 767-778 (2017)

3. Lou, L.L., Cheng, Z.Y., Guo, R., Yao, G.D., Song, S.J.: Alkaloids from Juglans Mandshurica maxim induce distinctive cell death in hepatocellular carcinoma cells. Nat. Prod. Res. 33 (6), 911-914 (2019)

4. Yao, D.L., Zhang, C.H., Luo, J., Jin, M., Zheng, M.S., Cui, J.M., Son, J.K., Li, G.: Chemical constituents from the leaves of Juglans mandshurica. Arch Pharm Res. 38 (4), 480-484 (2015)

5. Zhou, Y.Y., Gao, H.R., Song, H.J., Ma, D.D., Zhang, X.J., Sun, Y.P., Liu, Y., Wang, X.L., Yang, B.Y., Kuang, H.X.: Two new dammarane-type triterpenoids from the green walnut husks of Juglans mandshurica. J. Nat. Prod. Res.15, 1-8 (2020区

6. Zhu, X.D., Liu, Y., Wang, W.C., Dong, N.W., Zheng, S.Y.: Effect of Clear Painting on Surface Color Change of Thermochromic Wood Veneers. J. Northwest For. Univ. 34 (4), 223-229 (2019)

7. Shigaeva, J., Darr, D.: On the socio-economic importance of natural and planted walnut (Juglans regia L.) forests in the Silk Road countries: A systematic review. Forest Policy and Economics. 118, 102233-102249 (2020).

8. Zhang, Y.W., Lin, H., Bao, Y.L., Wu, Y., Yu, C.L., Huang, Y.X., Li, Y.X.: A new triterpenoid and other constituents from the stem bark of Juglans mandshurica. J. Biochem. Syst. Ecol. 44,136-140 (2012)

9. Zhou, Y., Yang, B., Jiang, Y. Z., Liu, Y., Liu, X., Wang, H.: Kuang Studies on cytotoxic activity against HepG-2 cells of naphthoquinones from green Juglans Husks of Juglans mandshurica. Molecules. 20 (9), 15572-15588 (2015)

10. Koichi, M., Erika, M., Takayuki, K., Masao, K.: Studies on the Constituents of Juglans Species. I. Structural Determination of (4S)- and (4R)-4-Hydroxy-A-tetralone Derivatives from the Fruit of Juglans mandshurica M AXIM. var. sieboldiana M AKINO.J. Chem. Pharm. Bull. 53 (8), 934-937 (2005)

11. Jin, M., Diao, S.B., Zhang, C.H., Cao, S., Sun, J.F., Li, P., Jiang, Z., Zheng, M.S., Li, G.: Two new diarylheptanoids isolated from the roots of Juglans mandshurica. Nat. Prod. Res. 29 (19), 1839-1844 (2015)

12. Xu, M.H., Yang, X.Y., Fu, M. R.: Combined Ultrasonic and Microwave Method for Juglone Extraction from Walnut Green Husk (Juglans nigra). J. Waste Biomass Valorization. 7 (5), 1159-1166 (2016)

13. Park, S.J., Kim, N.Y.,Yoo, G.J., Kim, S.N., Kwon, H.J., Jung, K.W., Oh, D.C., Lee, Y.H ,Kim, S.H.: Phenolics and neolignans isolated from the fruits of Juglans mandshurica and their effects on lipolysis in adipocytes. Phytochemistry. 137, 87-93 (2017). 
14. Sun, Z., Zhao, L.S. , Zuo, L.H., Qi, C., Zhao, P., Hou, X.H.: A UHPLC-MS/MS method for simultaneous determination of six flavonoids, gallic acid and 5,8-dihydroxy-1,4-naphthoquinone in rat plasma and its application to a pharmacokinetic study of Cortex Juglandis Mandshuricae extract. J. Chromatogr. B Anal. Technol. Biomed. Life Sci. 958, 55-62 (2014)

15. Khani, A., Meshkini, A.: Anti-proliferative Activity and Mitochondria-Dependent Apoptosis Induced by Almond and Walnut By-product in Bone Tumor Cells. Waste Biomass Valorization. 12, 1405-1416 (2021)

16. Gao, X.L.,Lin, H.,Zhao, W.,Hou, Y.Q.,Bao, Y.L.,Song, Z.B.,Sun, L.G.,Tian, S.Y.,Liu, B., Y.X.: JA, a new type of polyunsaturated fatty acid isolated from Juglans mandshurica, limits the survival and induces apoptosis of heptocarcinoma cells. Apoptosis. 21, 340-350 (2016)

17. Jiménez-Brenes, F. M ., López-Granados, F., Castro, A.I., Torres-Sánchez, J., Serrano, N., Peña, J.M.: Quantifying pruning impacts on olive tree architecture and annual canopy growth by using UAVbased 3D modelling. J. Plant Methods. 13 (1), 55-70 (2017)

18. Ersin, A.: A new insight into pruning strategy in the biennial cycle of fruiting: Vegetative growth at shoot and whole-tree level, yield and fruit quality of apple. Not. Bot. Horti Agrobot Cluj- Napoca. 45, 232-237 (2017)

19. Mohammadi, A., Mahmoudi, M.J., Rezaee, R.: Vegetative and reproductive responses of some apple cultivars (Malus domestica Borkh.) to heading back pruning. Int. J. AgriSci. 3, 628-635 (2013)

20. Cosmulescu, S., Trandafir, I., Achim, G., Bout, M., Bacit, A., Gruit, M.: Phenolics of green husk in mature Juglans fruits. Not Bot Horti Agrobot Cluj-Na. 38 (1), 53-56 (2010)

21. Stampar, F., Solar, A., Hudina, M.: Traditional Juglans liqueur - Cocktail of phenolics. Food Chem. 95, 627-631 (2006)

22. Gökalp, F.: The chemical activity of Juglone in different phases as a protective agent. J. Journal of Fluorine Chemistry. 242, 109701-109704 (2021)

23. Kao, C.C., Kung, P.H., Tai, C.J., Tsai, M.C., Cheng, Y.B., Wu, C.C.: Juglone prevents human platelet aggregation through inhibiting Akt and protein disulfide isomerase. J. Phytomedicine, 82, 153449153449 (2020)

24. Wu, C.Y., Wang, H., Fan, X.H., Yue, W., Wu, Q.N.: Waste Euryale ferox Salisb. Leaves as a Potential Source of Anthocyanins: Extraction Optimization, Identification and Antioxidant Activities Evaluation. Waste Biomass Valor. 11, 4327-4340(2020)

25. Orioli, M.L., Regazzoni, F., Saligari, C., Marinello, G., Rossoni, G., Aldini, M.: CariniCoffee silver skins as a source of polyphenols: high resolution mass spectrometric profiling of components and antioxidant activity. J. Funct. Foods. 20, 472-485 (2016)

26. Gîrzu, M., Fraisse, D., Carnat, A.P., Carnat, A., Lamaison, J.L.: High-performance liquid chromatographic method for the determination of juglone in fresh walnut leaves. Journal of Chromatography A. 805 (1-2), 315-318 (1998).

27. Laroze, L., Soto, C., Zúñiga, M.E.: Phenolic antioxidants extraction from raspberry waste assisted byenzymes. Electron J Biotechnol. 13 (6), 11-12 (2010) 
28. Yong, N., Bi, Z.H., Su, H., Yan, L.F.: Deep eutectic solvent (DES) as both solvent and catalyst for oxidation of furfural to maleic acid and fumaric acid. Green Chem. 21,1075-1079 (2019)

29. Cui, Q., Liu, J.Z., Xu, W.J., Kang, Y.F., Wang, X.Y., Li, Y.Y., Fu, Y.J.: Enhanced extraction and preconcentration of main target saponins from Panax notoginseng root using green and efficient formulated surfactant aqueous systems. J. Cleaner Prod. 186, 297-308 (2019)

30. Joanna, N., Kaveh, S., Marliya, I., Mohammed, M.F.: Approach for polygodial extraction from Pseudowintera colorata (Horopito) leaves using deep eutectic solvents ACS Sustain. Chem. Eng. 6, 862-871 (2018)

31. Douglas, G.H., Ran, Ye., Rachel, N.D., Matthew, J.C., Sai, V.P., Hugh, M. O., Volker S.U.: Protein extraction into the bicontinuous microemulsion phase of a Water/SDS/pentanol/dodecane winsor-III system: Effect on nanostructure and protein conformation. J. Colloids Surf. B. 160, 144-153 (2017)

32. Mehdi, J.J., Soleiman, A., Martin, G.S.: Microemulsion as nanoreactor for lutein extraction: Optimization for ultrasound pretreatment. J. Food Biochem. 43 (8),12929-12941 (2019)

33. Atefeh, A.R., Soleiman, A.: Extraction of lycopene using a lecithin-based olive oil microemulsion. J. Food Chem. 272, 568-573 (2019)

34. Liu, F., Yang, Y., Lu, Y., Shang, K., Lu, W., Zhao, X.: Extraction of Germanium by the AOT Microemulsion with N235 System. Ind. Eng. Chem. Res. 49, 10005-10008 (2010)

35. Guo, Y., Li, H.Y., Yuan, Y.H., Huang, J., Diao, J., Xie, B.: ME: An efficient way for simultaneous detoxification and resource recovery of hazardous wastewater containing $\mathrm{V}(\mathrm{V})$ and $\mathrm{Cr}(\mathrm{VI})$. J. Hazard. Mater. 386, 121948-121959 (2020)

36. Jalali, J.M., Abbasi, S.: Novel approach for lutein extraction: Food grade microemulsion containing soy lecithin \& sunflower oil. J. Innovative Food Sci. Emerging Technol. 66, 102505-102512 (2020)

37. Yang, X.Y., Jie, F.P., Wang, B.J., Bai, Z.S.: High-efficient synergistic extraction of Co (II) and Mn (II) from wastewater via novel microemulsion and annular centrifugal extractor. J. Sep. Purif. Technol. 209, 997-1006 (2018)

38. Aramburu, A., Bonifazi, E.L., Gerschenson, L.N., Rojas, A.M., Basanta, M.F.: Sweet cherry (Prunus avium) fibers extracted from microwave- and steam-blanched recovered fruits: Photo-antioxidant activity in milk proteins. Bioact. Carbohydr. Diet. Fibre. 24, 100247-100258 (2020)

39. Guo, Y., Li, H.Y., Shen, S., Wang, C.J., Diao, J., Xie, B.: Recovery of vanadium from vanadium slag with high phosphorus content via recyclable ME. Hydrometallurgy. 198,105509-105519 (2020)

40. Imen, B.A., Georgia, A., loanna, N., Maria, A., Moncef, N., Tahar, M., Gerasimos, L.: On the evaluation of different saccharification schemes for enhanced bioethanol production from potato peels waste via a newly isolated yeast strain of Wickerhamomyces anomalus. Bioresour. Technol. 289. 121614121623 (2019)

41. Kadouche, S., Farhat, M., Lounici, H., Fiallo, M., Sharrock, P., Mecherri, M., Hadioui, M.: LowCost Chitosan Biopolymer for Environmental Use Made from Abundant Shrimp Wastes. Waste Biomass Valorization. 8 (2), 401-406 (2017) 
42. Hajimohammadi, A., van Deventer, J.S.J.: Solid Reactant-Based Geopolymers from Rice Hull Ash and Sodium Aluminate. Waste Biomass Valorization. 8 (6), 2131-2140 (2017)

43. Lawrence, J.: Surfactant systems: microemulsions and vesicles as vehicles for drug delivery. Eur J. Drug Metab. Pharmacokinet. 19 (3), 257-269 (1994)

44. Du, Y.H., Jia, R.Y., Yin, Z.Q.: Acaricidal activity of extracts of neem (Azadirachta indica) oil against the larvae of the rabbit mite Sarcoptes scabiei var cuniculi in vitro. Vet. Parasitol. 157 (1-2),144-148 (2008)

45. Yuan, Y., Li, S.M., Mo, F.K.: Investigation of microemulsion system for transdermal delivery of mel oxicam. Int J Pharm. 32 (1), 117-123 (2006)

46. Silva Camilo, J.V., Martelloti, R.R., Costa, J.A., Mansur, C.R.E.: Development of Oil-in-Water Microemulsions and Evaluation of Its Presence in the Treatment of Produced Water. Journal of Nanoscience and Nanotechnology. 19 (8), 8143-8150 (2019)

47. Liu, W.L., Liu, C.M., Liu, W., Chen, H.L., Liu, J.H.: Study on Preparation of O/W MCFA Micro-emulsion and Its Characteristics. Food Science. 30 (6), 102-105 (2009)

48. Brown, D.G., Jaffé, P.R.: Effects of nonionic surfactants on the cell surface hydrophobicity and apparent hamaker constant of a Sphingomonas sp. Environ. Sci. Technol. 40 (1), 195-201(2006)

49. 49. Candioti, L.V., De Zan, M.M., Cámara, M.S., Goicoechea, H.C.: Experimental design and multiple response optimization. Using the desirability function in analytical methods development. Talanta. 15 (124), 123-138 (2014)

50. Sun, H.Y, Li, C.Y., Ni, Y.J., Yao, L.P., Jiang, H.W., Ren, X.T., Fu Y.J., Zhao, C.J.: Ultrasonic/microwaveassisted extraction of polysaccharides from Camptotheca acuminata fruits and its antitumor activity. Carbohydr. Polym. 15 (206), 557-564 (2019)

51. Zhang, S., Feng, L.L., Peng, X.X., Mao, M.M., Chi, Y., Wang, F.: Effect of Sludge Pellets Addition on Combustion Characteristics and Ash Behaviour of Municipal Solid Waste. Waste Biomass Valorization. 11 (10), 5351-5361 (2020)

\section{Tables}

Due to technical limitations, tables are available as downloads in the supplementary files.

\section{Figures}



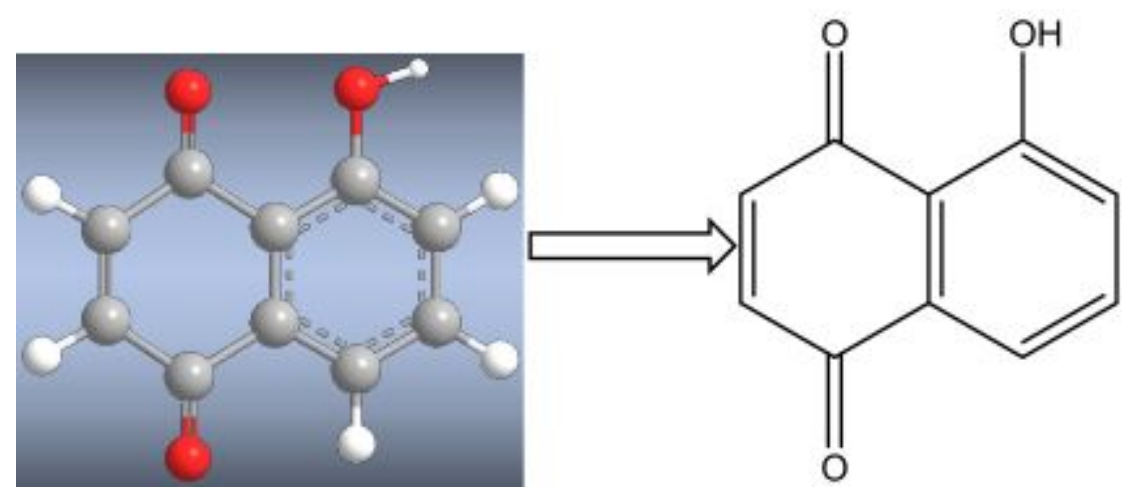

Figure 1

The structures of juglone.
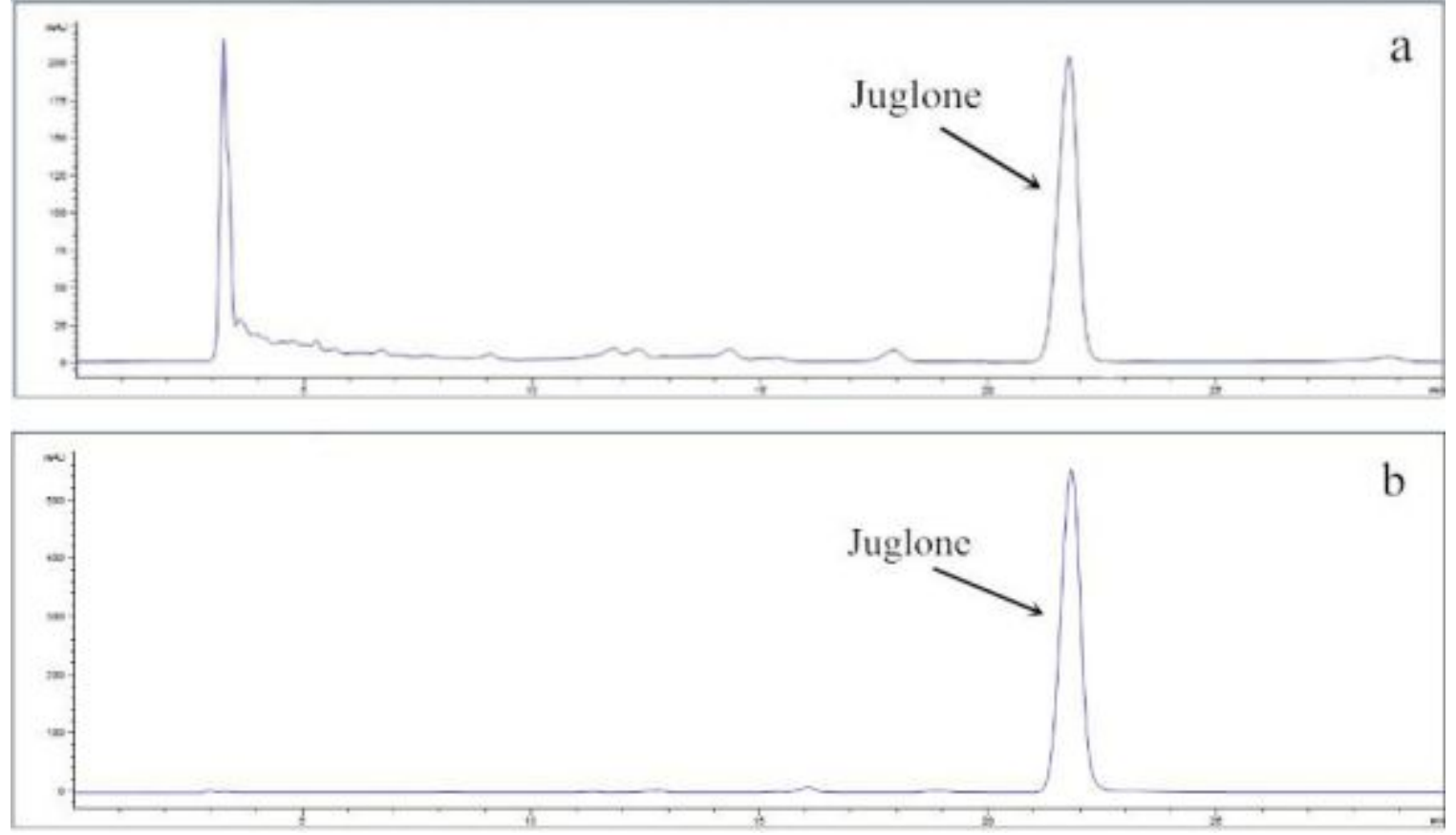

\section{Figure 2}

HPLC chromatograms of juglone of Juglans mandshurica waste branches (a) and standard (b). 

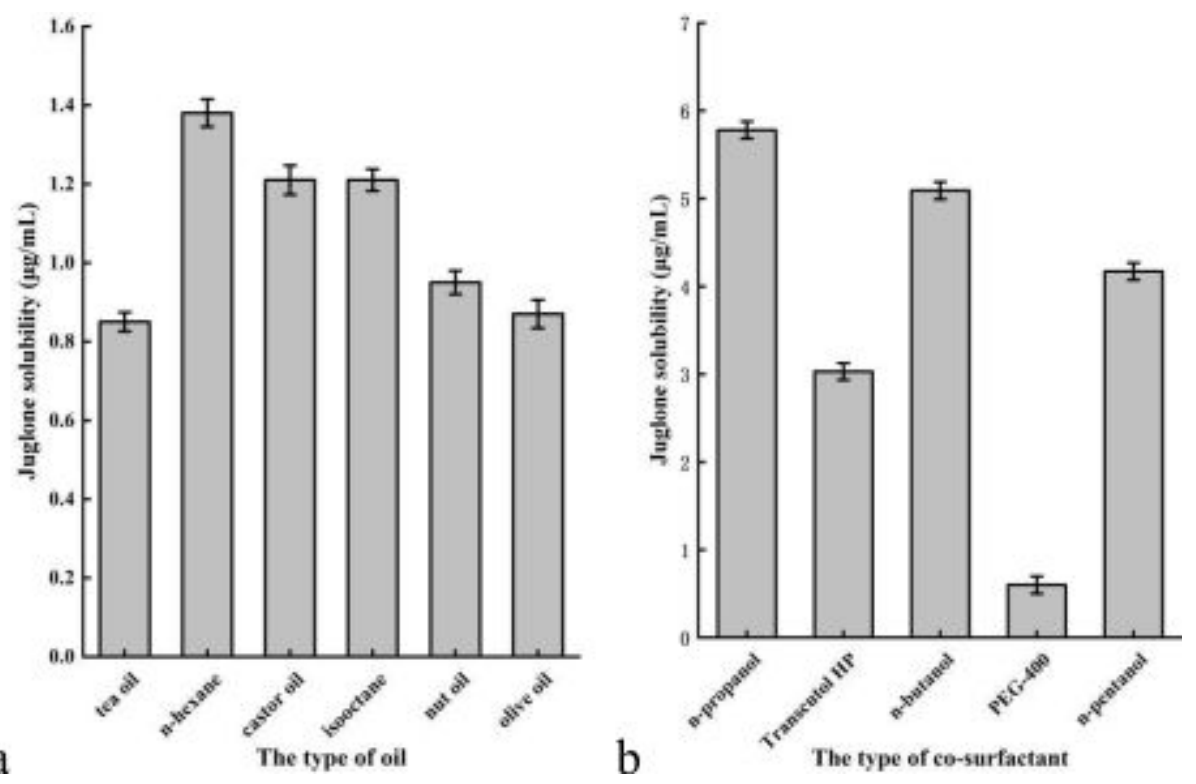

Figure 3

Solubility of juglone in the components of accessories.
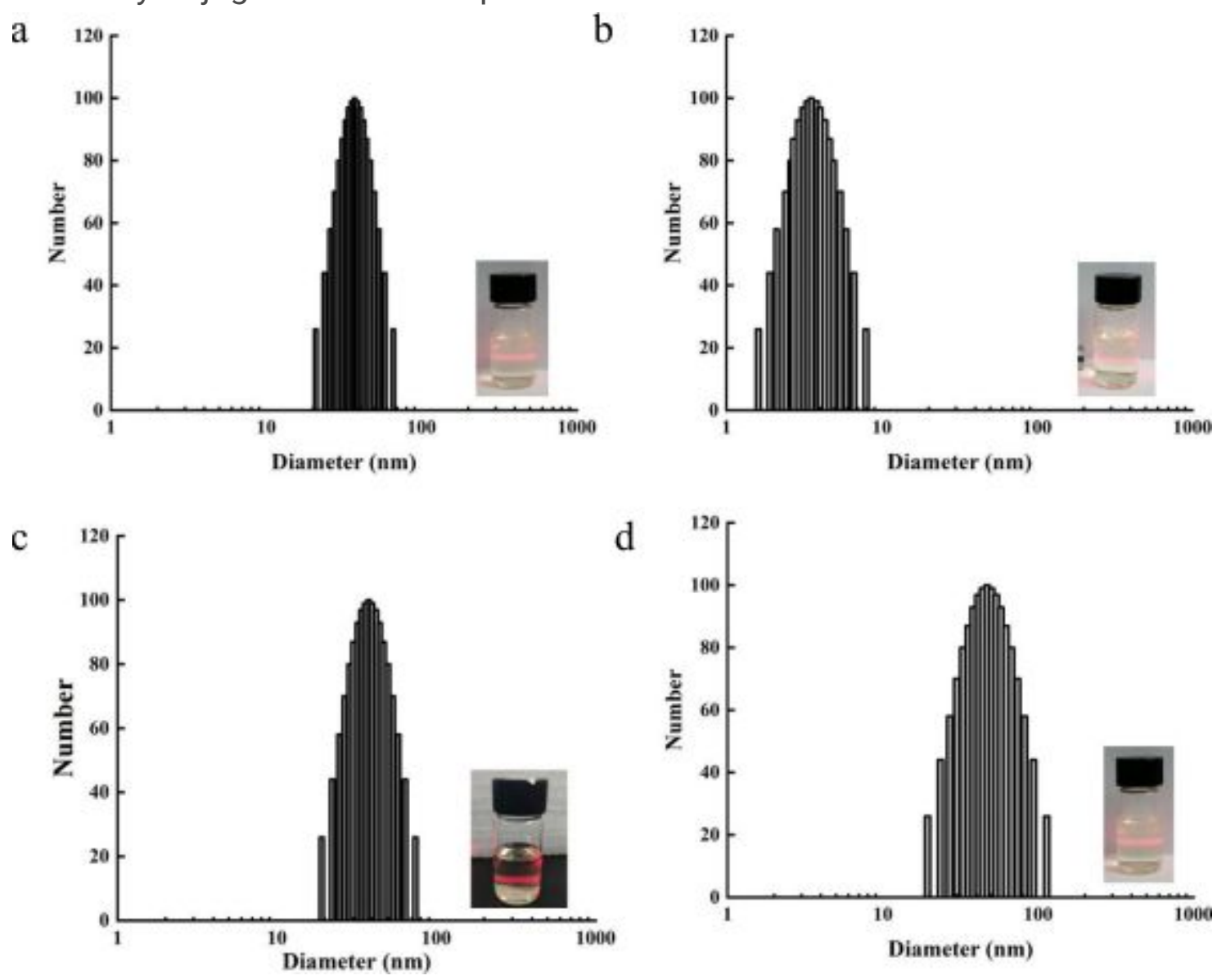

Figure 4

Diagram of particle size and Tyndall effect. 


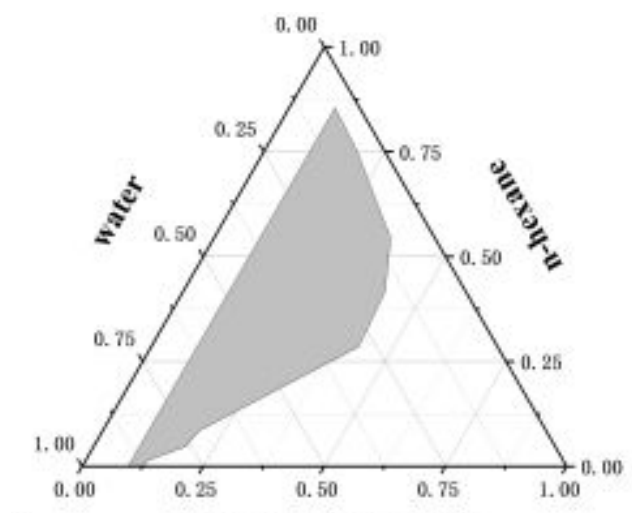

a

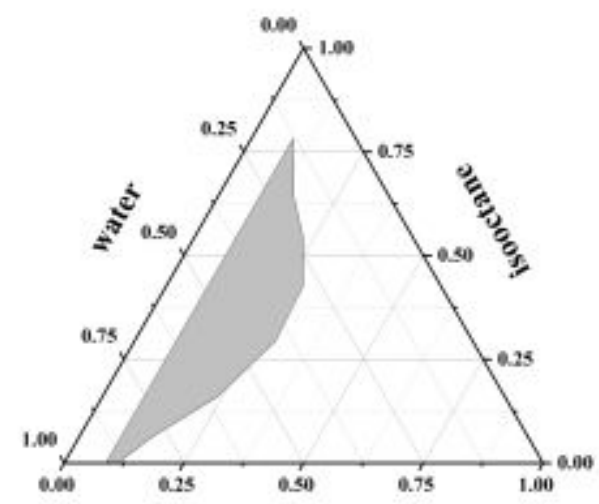

c

Tween 80+n-propanol

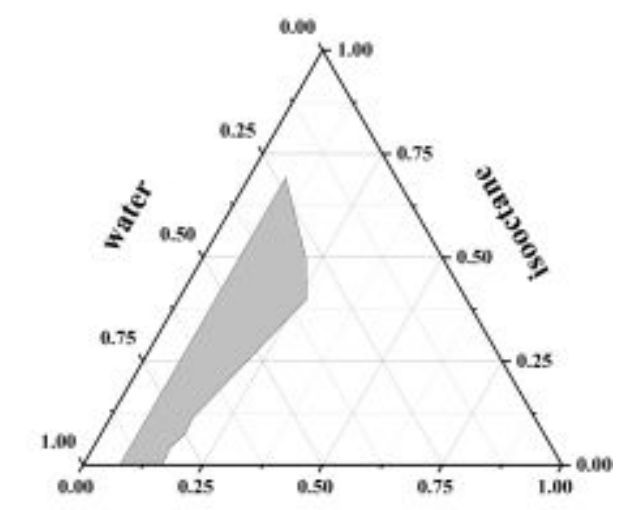

b

Tween 80+n-butanol

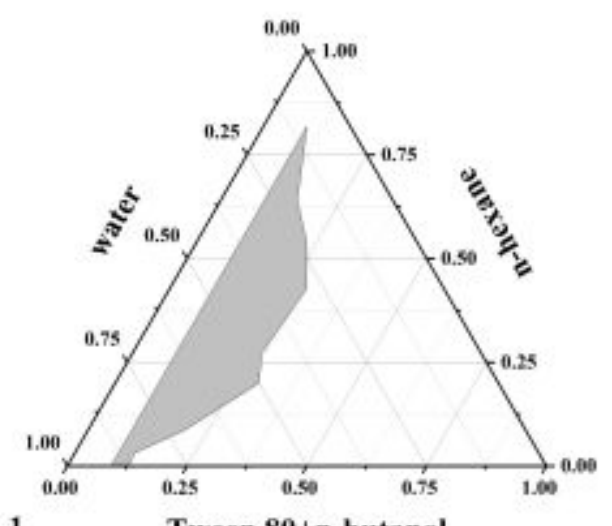

d

\section{Figure 5}

Pseudo-ternary phase diagrams of four systems microemulsions.

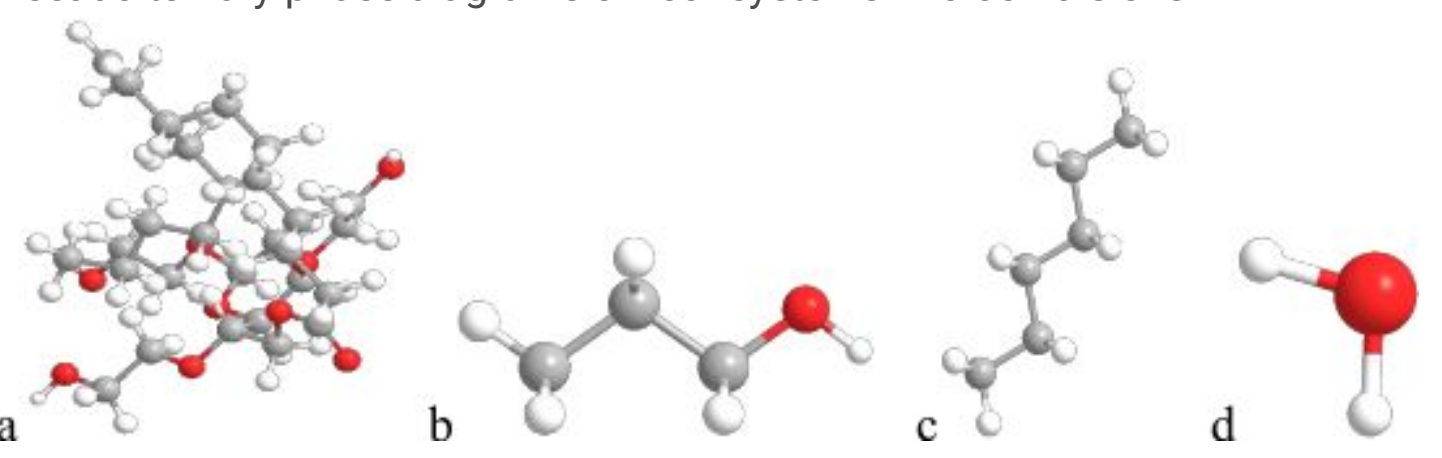

\section{Figure 6}

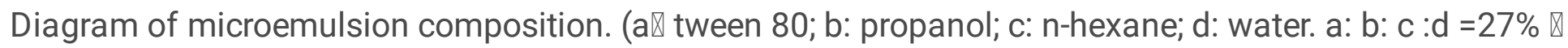
$13.5 \% \square 4.5 \% \otimes 55 \%)$. 


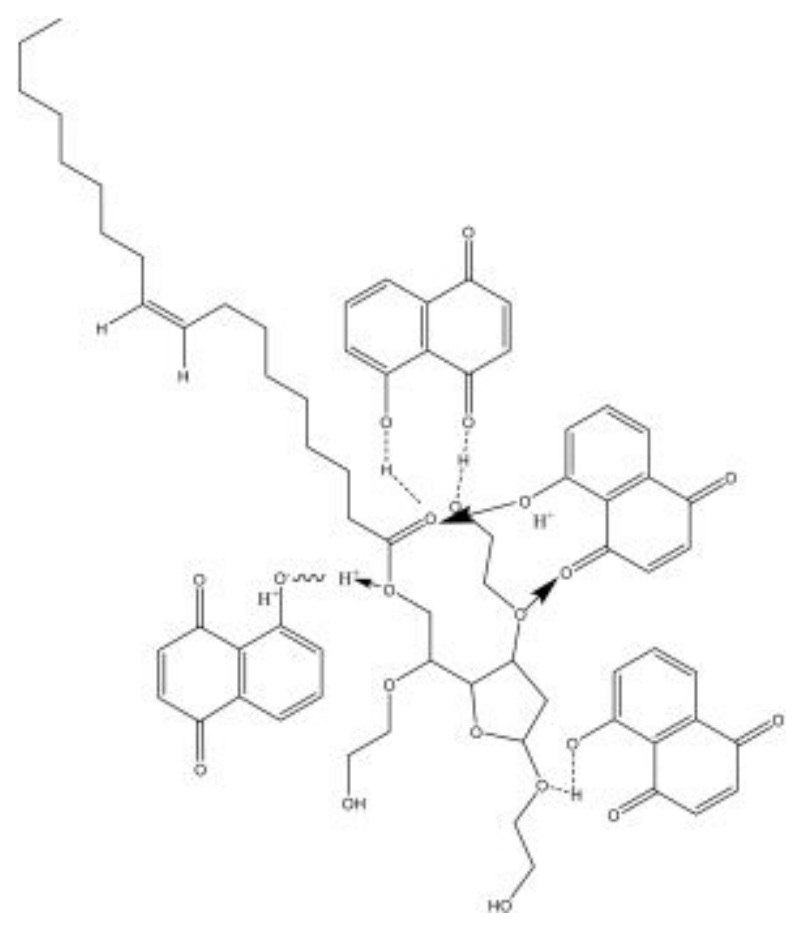

\section{Figure 7}

Diagram of juglone extraction (:hydrogen bond, $\rightarrow$ : hydrogen bond, : electrostatic interaction).

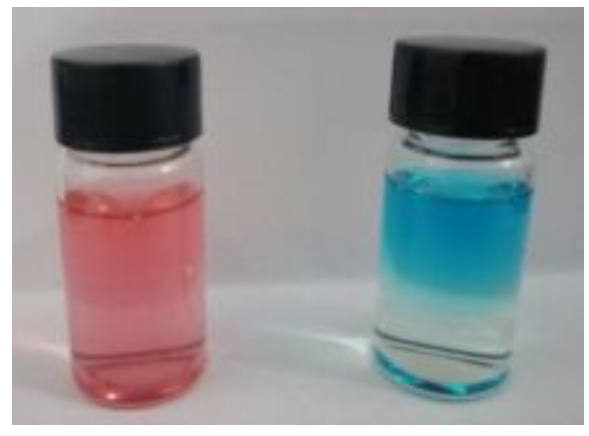

Figure 8

Photo graph of dye diffusion (24 hours after dye addition, leftखSudan red; right: Methylene blue) 

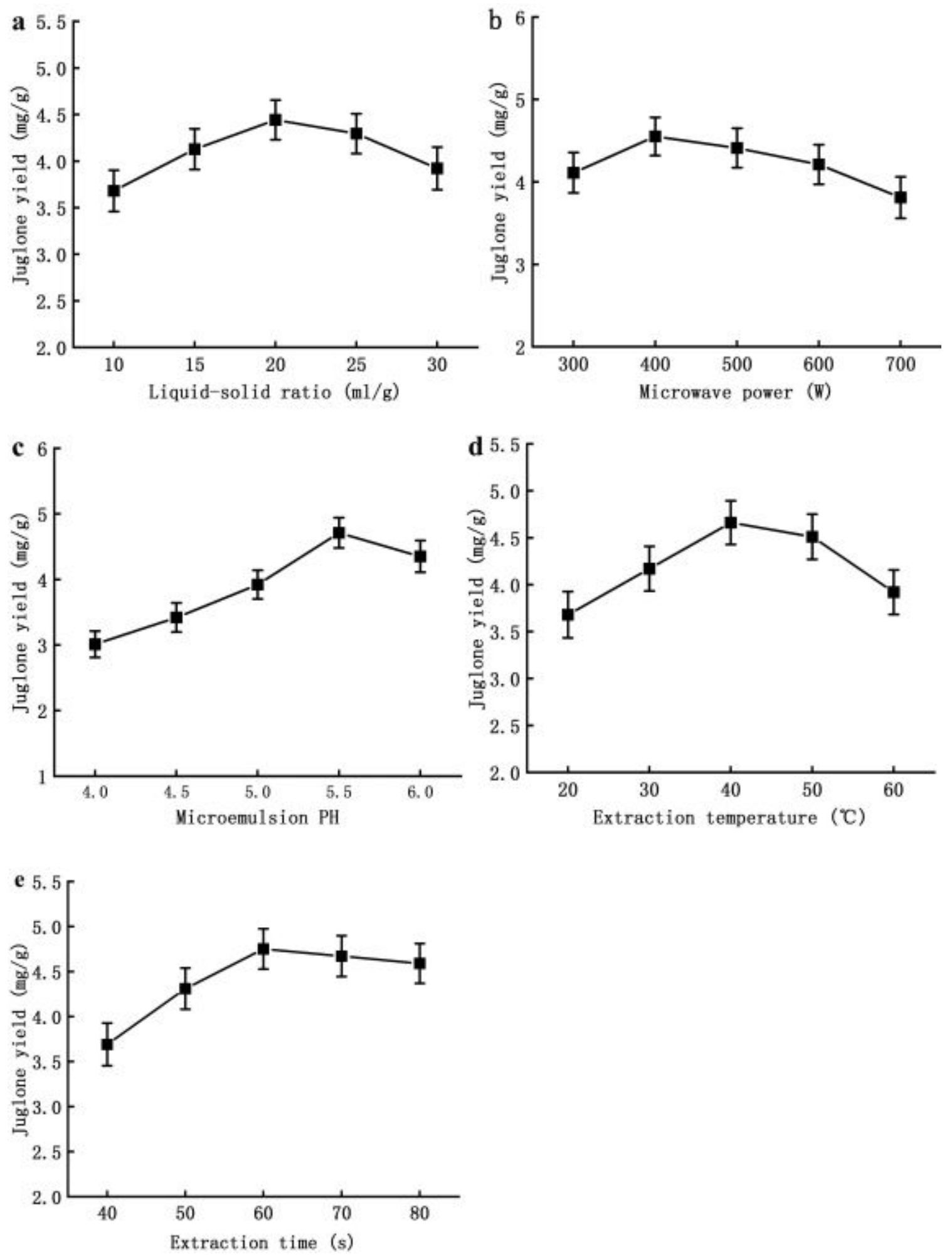

Figure 9

Effects of different extraction parameters on the yield of juglone. (a: liquid-solid ratio; b: extraction power; c: microemulsion $\mathrm{PH}$; d: extraction temperature; e: extraction time). 

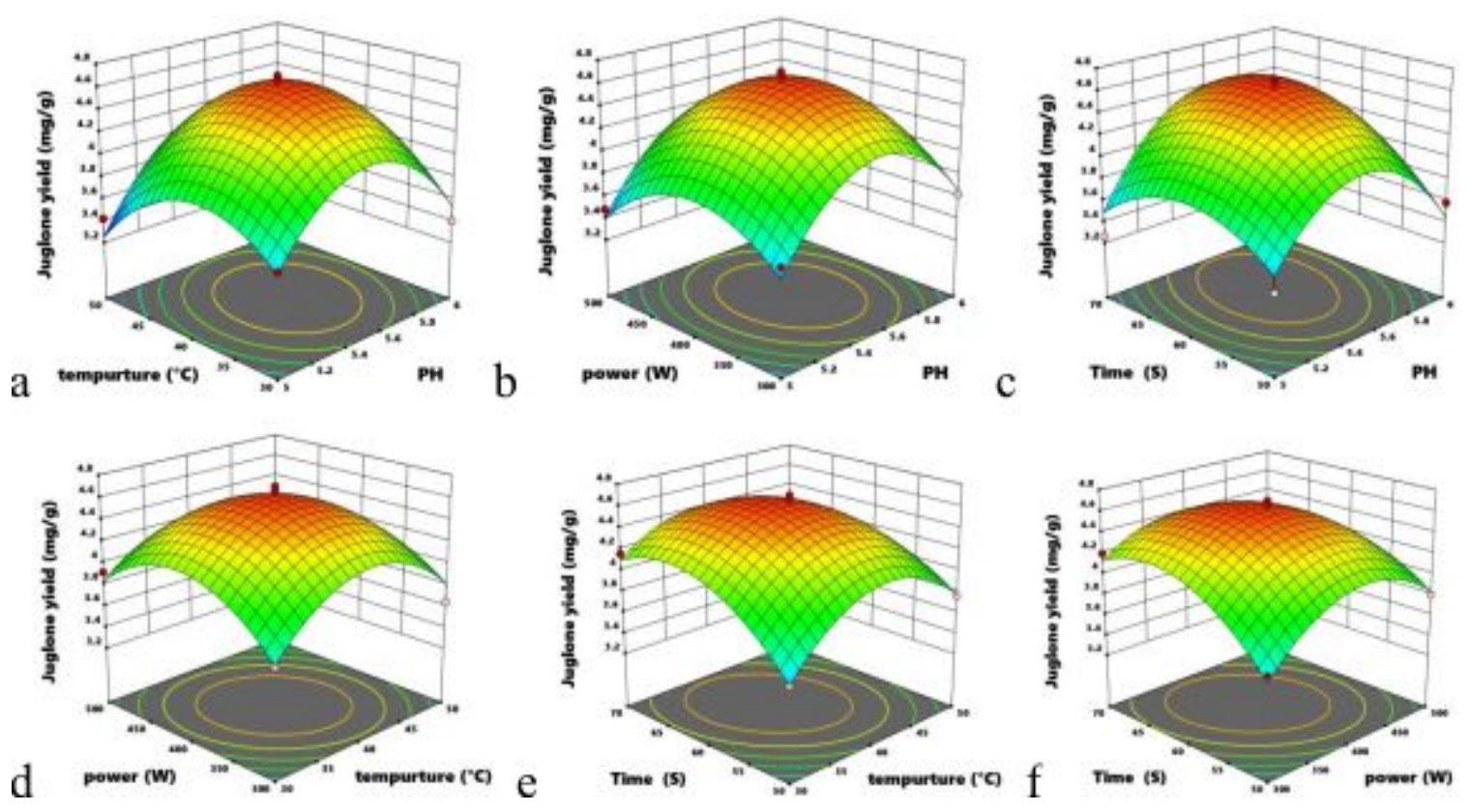

Figure 10

RSM for juglone yield in branches of Juglans mandshurica . a: varying microemulsion $\mathrm{PH}$ and extraction temperature $\left({ }^{\circ} \mathrm{C}\right)$. b: varying microemulsion $\mathrm{PH}$ and extraction power $(\mathrm{W})$. c: varying microemulsion $\mathrm{PH}$ and extraction time (s). d: extraction temperature $\left({ }^{\circ} \mathrm{C}\right)$ and extraction power $(\mathrm{W})$. e: varying extraction temperature $\left({ }^{\circ} \mathrm{C}\right)$ and extraction time. $f$ varying extraction power and extraction time.

\section{Supplementary Files}

This is a list of supplementary files associated with this preprint. Click to download.

- Table1.pdf

- Table2.pdf

- Table3.pdf

- Table4.pdf

- Table5.pdf

- Table6.pdf

- Table7.pdf

- formula.docx 